CENDEKIA UTAMA

Jurnal Keperawatan dan

Kesehatan Masyarakat

STIKES Cendekia Utama Kudus
P-ISSN 2252-8865

E-ISSN 2598-4217

Vol. 9, No. 2 - Oktober, 2020

Tersedia Online:

htpp://jurnal.stikescendekiautamakudus.ac.id

\title{
KORELASI LAMA MENDERITA HIPERTENSI DENGAN TINGKAT KECEMASAN PENDERITA HIPERTENSI
}

\author{
Fitri Suciana $^{1}$, Nur Wulan Agustina ${ }^{2}$, Mifta Zakiatul ${ }^{3}$ \\ 1,2,3 STIKES Muhammadiyah Klaten \\ Email: andhikazka@gmail.com
}

\begin{abstract}
ABSTRAK
Hipertensi atau tekanan darah tinggi adalah peningkatan tekanan darah sistolik lebih dari 140 $\mathrm{mmHg}$ dan tekanan darah diastolik lebih dari $90 \mathrm{mmHg}$. Jumlah penyandang hipertensi terus meningkat setiap tahunnya, diperkirakan pada tahun 2025 akan ada 1,5 miliar orang yang terkena hipertensi, dan setiap tahunnya 10,44 juta orang meninggal akibat hipertensi dan komplikasinya. Lama menderita hipertensi akan menyebabkan beberapa komplikasi seperti gagal jantung, gagal ginjal, stroke. Namun selain menimbulkan masalah fisik, hipertensi juga dapat menyebabkan masalah psikologis seperti kecemasan. Tujuan dari penelitian ini adalah mengetahui adakah korelasi antara lama menderita hipertensi dengan tingkat kecemasan penderita hipertensi. Jenis penelitian yang digunakan adalah deskripsi analitik dan menggunakan pendekatan cross sectional dengan jumlah sampel sebanyak 56 responden. Pengambilan data pada penelitian ini menggunakan kuesioner HARS yang dianalisis dengan menggunakan uji kendall tau. Hasilnya adalah sebagian besar dengan hipertensi sedang dengan TD 160-180 mmHg sebanyak 28 responden, lama menderita hipertensi $>11$ tahun sebanyak 24 responden, tingkat kecemasan penderita dengan tingkat kecemasan ringan sebanyak 31 responden. Nilai kendall's tau antara lama menderita hipertensi dan tingkat kecemasan diketahui sebesar 0,417 dengan nilai signifikan 0,000 $(<0,05)$. Kesimpulan pada penelitian ini adalah adanya hubungan antara lama menderita hipertensi dengan tingkat kecemasan.
\end{abstract}

Kata Kunci: Hipertensi, lama menderita hipertensi, tingkat kecemasan

\section{ABSTRACT}

Hypertension or high blood pressure is an increase in systolic blood pressure more than 140 $\mathrm{mmHg}$ and diastolic blood pressure of more than $90 \mathrm{mmHg}$. The number of people with hypertension continues to increase every year, it is estimated that by 2025 there will be 1.5 billion people afeected by hypertension and every ten year 44 milliom people died from hypertension and its complications. Long suffering from hypertension will cause several complications such as congestive heart failure, chronic kidney disease, and stroke. Hypertension can also cause psychological problems such as anxiety. The purpose of this study 
was to determine whether there was a correlation between lenght of time suffering from hypertension and the anxierty level of hypertensive sufferers. The method is analytic description and using a cross sectional approach. Total sample of 58 respondents and using the Hars questionaire which was analyzed using the Kendall Tau test. The result is that most of them with moderate hypertension with blood pressure 160-180 mmHg as many as 28 respondents, long suffering hypeetension $>11$ years as many as 24 respondents, the anxiety level of patients with mild anxiety levels was 31 respondents. The kendall's tau value between the lenght of suffering from hypertension and the level of anxiety is known to be equal to 0.417 with a significant value of $0.000(<0.05)$ the conclusion is there is a relationship between long suffering from hypertension and anxiety.

Keywords: Hypertension, progressive muscle relaxation therapy, blood pressure

\section{LATAR BELAKANG}

Hipertensi atau tekanan darah tinggi adalah peningkatan tekanan darah sistolik lebih dari $140 \mathrm{mmHg}$ dan tekanan darah diastolik lebih dari $90 \mathrm{mmHg}$ pada dua kali pengukuran dengan selang waktu lima menit dalam keadaan cukup istirahat/tenang. Penderita Hipertensi sekitar 972 juta orang atau 26,4\% orang di seluruh dunia mengidap hipertensi, angka ini kemungkinan akan meningkat menjadi 29,2\% di tahun 2025. Dari 972 juta pengidap hipertensi, 333 juta berada di negara maju dan 639 sisanya berada di negara berkembang, termasuk Indonesia. Jumlah penyandang hipertensi terus meningkat setiap tahunnya, diperkirakan pada tahun 2025 akan ada 1,5 miliar orang yang terkena hipertensi, dan setiap tahunnya 10,44 juta orang meninggal akibat hipertensi dan komplikasinya (Arifin, 2016).

Hipertensi secara nasional (25,8 persen), jika dibanding hasil riskesdas tahun 2007 (31,7/1000) menunjukkan adanya penurunan angka prevalensi, namun hal ini tetap perlu di waspadai mengingat hipertensi merupakan salah satu faktor risiko penyakit degeneratif antara lain penyakit jantung, stroke dan penyakit pembuluh darah lainnya. Pengukuran tekanan darah merupakan salah satu kegiatan deteksi dini terhadap faktor risiko PTM seperti Hipertensi, Stroke, Jantung, Kelainan Fungsi Ginjal atau yang lainnya. Kegiatan ini bisa dilaksanakan di setiap fasilitas. Kematian didunia mencapai 53,3 juta penyebabnya akibat kardovaskuler sebesar 33,1\%. Total 1,7 juta kematian indonesia didapatkan faktor resiko penyebab kematian adalah tekanan darah (hipertensi) sebesar 23,7\% (Kemenkes RI,2013).

Hipertensi atau tekanan darah tinggi merupakan salah satu penyebab utama penyakit jantung dan stroke. Pada setiap tahunya hipertensi penyebab kematian pada angka 9,4 juta orang yang diakibatkan penyakit jentung dan stroke, dan apabila di gabungkan, penyakit jantung dan stroke ini merupakan penyebab penyakit mematikan nomor satu di dunia. Hipertensi juga mempengaruhi adanya risiko gagal ginjal, dan lebih banyak lagi kondisi-kondisi lainya. Hipertensi sering kali terjadi bersama dengan faktor risiko lainya seperti hanya obesitas, diabetes, dan kolestrol tinggi yang kerap meningkatkan risiko kesehatan. Peningkatan tekanan darah yang berlangsung dalam jangka waktu lama (persisten) dapat menimbulkan kerusakan pada ginjal (gagal ginjal), jantung (penyakit jantung koroner) dan otak (menyebabkan) bila tidak dideteksi secara dini dan mendapat pengobatan yang memadai (Riskesdas, 2013).

Resiko lain yang diakibatkan karena penyakit hipertensi adalah kecemasan. Kecemasan yang paling sering terjadi disebabkan karena hipertensi. Hipertensi merupakan penyakit yang menyebabkan masalah-masalah baru, seperti stroke, gagal jantung, ginjal dan pastinya semuanya berdampak terjadinya kematian.Sehingga perlu 
adanya pencegahan lebih dini agar hipertensi tidak menyebabkan permasalahan baru bagi penderita. Hal inilah yang membuat penderita hipertensi cemas akan keadaan dirinya. Kekhawatiran seseorang akan timbulnya suatu masalah-masalah baru yang ada pada hipertensi akan menyebabkan gangguan mental emosional atau perasaan yang sering kita jumpai salah satunya adalah kecemasan. Perasan itu muncul akibat ketakutan dan ketidaktahuan seseorang tentang apa yang di alaminya dan apa yang akan terjadi selanjutnya (Istirokhah,2017). Seorang penderita hipertensi mungkin akan menjadi cemas disebabkan penyakit hipertensi yang cenderung memerlukan pengobatan yang relatif lama, risiko komplikasi dan dapat memperpendek usia (Hawari,2013). Risiko komplikasi pada hipertensi yaitu stroke, retinopati diabetic, kerusakan ginjal dan jantung coroner (Wijaya, 2013). Kecemasan dapat didefinisikan gangguan alam perasaan yang ditandai dengan perasaan ketakutan atau kekhawatiran yang mendalam dan berkelanjutan, tidak mengalami gangguan dalam menilai kenyataan, kepribadian masih tetap utuh atau tidak mengalami keretakan kepribadian normal. Tekanan mental atau kecemasan diakibatkan oleh kepedulian yang berlebihan akan masalah yang sedang dihadapi nyata ataupun yang dibayangkan mungkin terjadi. Kecemasan yang paling sering terjadi disebabkan karena penyakit, salah satunya hipertensi. Sehingga perlu adanya pencegahan lebih dini agar hipertensi tidak menyebabkan permasalahan baru bagi pasien. Hal inilah yang membuat pasien dan keluarga cemas akan keadaan pasien (Hawari, 2013).

\section{METODE PENELITIAN}

Jenis penelitian yang digunakan adalah deskripsi analitik dan menggunakan pendekatan cross sectional. Populasi dalam penelitian ini adalah lansia yang mengikuti posyandu di desa Grogol sebanyak 68 penderita hipertensi. Pada penelitian ini jumlah sampel sebnayak 58 responden dengan teknik pengambilan sampel dalam penelitian ini adalah purposive sampling yang sesuai dengan kriteria inklusi dalam penelitian. Pengambilan data pada penelitian ini menggunaka kuesioner HARS yang dianalisis dengan menggunakan uji kendall tau.

\section{HASIL DAN PEMBAHASAN Karakteristik Responden}

Tabel 1

Rerata umur responden di Desa Grogol tahun $2020(n=58)$

\begin{tabular}{cccccc}
\hline Variabel & $\mathrm{n}$ & Min & Max & Mean & Std.Deviasi \\
\hline Umur & 58 & 45 & 80 & 62.41 & 10.208 \\
\hline
\end{tabular}

Berdasarakan tabel 1 hasil penelitian yang diperoleh di Desa Grogol diketahui rata-rata umur responden dalam penelitian ini adalah 62,41 dan standar devisiasi $\pm 10,208$. Individu yang berumur diatas 60 tahun, 50-60\% mempunyai tekanan darah lebih besar atau sama dengan 140/90 mmHg. Hal itu merupakan pengaruh degenerasi yang terjadi pada orang yang bertambah usianya (Suliswati, 2012).

Dalam perkembangan lanjut usia penurunan fungsi tubuh akan banyak terjadi. Penurunan fungsi tubuh pada lansia diakibatkan karena proses penuaan. Proses penuaan merupakan proses yang mengakibatkan perubahan-perubahan meliputi perubahan fisik, psikologis, dan psikososial. Pada perubahan fisiologis terjadi penurunan sistem 
kekebalan tubuh dalam menghadapi gangguan dari dalam maupun luar tubuh, salah satu gangguan kesehatan yang paling banyak dialami pada lansia adalah pada sistem kardiovaskuler dimana terjadi penyempitan pada pembuluh darah akibatnya aliran darah terganggu sehingga memicu peningkatan tekanan darah. Semakin tinggi umur seseorang maka semakin beresiko terkena berbagai macam penyakit baik dari dalam tubuh maupun dari luar tubuh (Lumi, 2018).

Dalam penelitian ini sebagian besar responden yang mengikuti posyandu berumur lebih dari 60 tahun. Hal ini sejalan dengan penelitian berdasarkan frekuensi mengenai umur responden terbanyak adalah pada umur 60-74 tahun sebanyak 36 orang $(59,0 \%)(8)$.

Tabel 2

Distribusi Frekuensi tekanan darah di Desa Grogol tahun $2020(n=58)$

\begin{tabular}{ccc}
\hline Variabel & Frekuensi (f) & Persentase (\%) \\
\hline Hipertensi Ringan & 26 & 44.8 \\
Hipertensi Sedang & 28 & 48.3 \\
Hipertensi Berat & 4 & 6.9 \\
\hline Total & 58 & 100.0 \\
\hline
\end{tabular}

Berdasarkan tabel 2 diketahui jumlah responden yang menderita hipertensi sebagaian besar adalah hipertensi sedang (160-180 $\mathrm{mmHg}$ ) sebanyak 28 (48,3\%). Hipertensi atau Tekanan darah tinggi adalah peningkatan tekana persistem pada pembuluh darah arteri, dimana tekanan darah sistolik di atas $140 \mathrm{mmHg}$ dan tekan diastolic diatas $90 \mathrm{mmHg}$. Hipertensi merupakan salah satu penyakit paling mematikan di dunia. Hipertensi tidak dapat secara langsung membunuh penderitanya, melainkan hipertensi memicu terjadinya penyakit lain yang tergolong kelas berat dan mematikan serta memberi gejala yang berlanjut untuk suatu target organ, seperti stroke untuk otak, penyakit jantung koroner untuk pembuluh darah jantung dan untuk otot jantung. Tekanan darah akan meningkat seiring dengan bertambahnya umur seseorang. Individu yang berumur diatas 60 tahun, 50-60\% mempunyai tekanan darah lebih besar atau sama dengan 140/90 mmHg. Hal itu merupakan pengaruh degenerasi yang terjadi pada orang yang bertambah usianya (Susila, 2015).

Tabel 3

Distribusi Frekuensi jenis kelamin di Desa Grogol tahun $2020(n=58)$

\begin{tabular}{ccc}
\hline Variabel & Frekuensi (f) & Persentase (\%) \\
\hline Laki-laki & 17 & 29.3 \\
Perempuan & 41 & 70.7 \\
\hline Total & 58 & 100.0 \\
\hline
\end{tabular}

Berdasarkan tabel 3 diketahui distribusi frekuensi data demografi responden sebagian besar berjenis kelamin perempuan sebanyak 41 orang $(70,7 \%)$. Dalam penelitian ini jumlah penderita hipertensi yang berjenis kelamin perempuan lebih banyak karena populasi perempuan di desa Grogol lebih banyak dari pada lakilaki.Tekanan darah cenderung meningkat pada perempuan setelah menopause, hal ini 
disebabkan oleh faktor psikologi dan adanya perubahan dalam diri wanita tersebut seperti perubahan hormon estrogen dan progesteron (Suliswati, 2012).

Hipertensi atau tekanan darah lebih banyak menyerang wanita pada usia setelah 55 tahun, sekitar $60 \%$ penderita hipertensi adalah wanita. Hal ini berkaitan dengan perubahan hormon setelah menopause (Lumi, 2018). Hal ini sejalan dengan penelitian Jenis kelamin perempuan penelitian ini lebih banyak mengalami hipertensi dibandingkan laki-laki, dikarenakan mereka masih sulit dalam mengontrol kesehatannya. Apalagi banyak didapatkan yang sudah mengalami menopause. Selain sistem tubuh dan hormon yang menurun, stress karena keadaan dan lingkungan juga sangat mempengaruhinya (Rizal,2019).

\section{Tabel 4}

Distribusi Frekuensi pendidikan di Desa Grogol tahun $2020(n=58)$

\begin{tabular}{ccc}
\hline Tabel & Frekuensi (f) & Persentase (\%) \\
\hline Tidak sekolah & 24 & 48.3 \\
SD & 22 & 37.9 \\
SMP & 4 & 6.9 \\
SMA & 4 & 6.9 \\
\hline Total & 58 & 100.0 \\
\hline
\end{tabular}

Berdasarkan tabel 4 diketahui distribusi frekuensi data demografi pendidikan responden paling banyak adalah tidak sekolah sebanyak 24 orang (48,3\%). Artinya sebagian besar responden berada dalam tingkat pengetahuan rendah. Menurut peneliti tingkat pendidikan respoden yang rendah berdampak terhadap motivasi dan kesadaran untuk mencegah terjadinya hipertensi.

Seseorang yang mengalami hipertensi dengan tingkat pendidikan yang sangat rendah disebabkan karena kurangnya pengetahuan tentang kesehatan maupun penyakit yang dialaminya sehingga sulit untuk mengontrol masalah kesehatannya. Tingkat pendidikan yang rendah pada responden yang didapatkan sangat berpengaruh besar terhadap hipertensi yang dideritanya, karena kurangnya wawasan tentang kesehatan menyebabkan cara berfikir yang kurang efektif dalam menanggapi dan menjaga berhubungan dengan masalah masalah kesehatannya.

\section{Tabel 5}

Distribusi Frekuensi pekerjaan di Desa Grogol tahun 2020 (n=58)

\begin{tabular}{ccc}
\hline Variabel & Frekuensi (f) & Persentase (\%) \\
\hline Tidak bekerja & 29 & 50.0 \\
Swasta & 10 & 17.2 \\
Buruh & 19 & 32.8 \\
\hline Total & 58 & 100.0 \\
\hline
\end{tabular}

Berdasarkan tabel 5 diketahui distribusi frekuensi data demografi pekerjaan responden pada penelitian ini paling banyak tidak bekerja sebanyak 29 orang 50,0\%). Dalam penelitian ini sebagian besar responden tidak bekerja dikarenakan karena kondisi yang sudah tua dan karena sakit dan tidak bisa melanjutkan bekerja. Pekerjaan didefinisikan sebagai sejauh mana seseorang mengidentifikasi secara psikologis dengan pekerjaanya atau pentingnya pekerjaan dalam citra diri individu. Menurut peneliti 
pekerjaan sangat penting dalam mengembangkan ekonomi yang ada karna dengan pekerjaan yang baik maka dapat memenuhi kebutuhan hidup seseorang atau keluarga lebih baik lagi (Suliswati,2012). Hasil penelitian ini sejalan dengan penelitian Berdasarkan frekuensi mengenai pekerjaan responden terbanyak adalah 57 orang (93,4\%) adalah responden yang tidak bekerja (Rahmayanti, 2018).

Tabel 6

Distribusi Frekuensi komplikasi penyakit di Desa Grogol tahun 2020

\begin{tabular}{ccc}
\hline Variabel & Frekuensi (f) & Persentase (\%) \\
\hline Tidak Ada komplikasi & 44 & 75.9 \\
Diabetes mellitus & 11 & 19.0 \\
Stroke & 3 & 5.2 \\
\hline Total & 58 & 100.0 \\
\hline
\end{tabular}

Berdasarkan tabel 6 diketahui distribusi frekuensi data demografi responden paling banyak tidak mempunyai komplikasi penyakit sebanyak 44 orang $(75,9 \%)$. Dalam penelitian ini banyak responden yang tidak mengalami komplikasi karena menjaga pola makan atau diet untuk hipertensi. Selain seluruh responden rutin mengkonsumsi obat sehingga bisa mengurangi resiko komplikasi.

Seorang yang lama menderita hipertensi mungkin akan menjadi cemas disebabkan penyakit hipertensi yang cenderung memerlukan pengobatan yang relatif lama, terdapat risiko komplikasi dan dapat memperpendek usia (Hawari, 2013). Tekanan darah tinggi jika tidak ditangani atau diobati, dalam jangka panjang akan merusak pembuluh darah diseluruh tubuh, kompilkasi yang bisa ditimbulkan karena hipertensi adalah Stroke, retinopati diabetik, kerusakan ginjal, gagal ginjal dan jantung coroner (Wijaya, 2013). Dalam penelitian Hipertensi merupakan penyakit yang menyebabkan masalah-masalah baru, seperti stroke, gagal jantung, ginjal dan pastinya semuanya berdampak terjadinya kematian. Sehingga perlu adanya pencegahan lebih dini agar hipertensi tidak menyebabkan permasalahan baru bagi penderita. Hal inilah yang membuat penderita hipertensi cemas akan keadaan dirinya (Widodo,2018).

Tabel 7

Distribusi Frekuensi Lama Menderita Hipertensi di Desa Grogol tahun 2020 (n=58)

\begin{tabular}{ccc}
\hline Variabel & $\begin{array}{c}\text { Frekuensi } \\
\text { (f) }\end{array}$ & Persentasi (\%) \\
\hline 1-5 tahun & 15 & 25.9 \\
6-10 tahun & 19 & 32.8 \\
$>11$ tahun & 24 & 41.4 \\
\hline Total & 58 & 100.0 \\
\hline
\end{tabular}

Berdasarkan tabel 7 diketahui distribusi frekuensi data demografi responden dengan lama menderita hipertensi sebagian besar $>11$ tahun sebanyak 24 orang (41,4\%). Tekanan darah akan meningkat seiring dengan bertambahnya umur seseorang. Individu yang berumur diatas 60 tahun, 50-60\% mempunyai tekanan darah lebih besar atau sama dengan $140 / 90 \mathrm{mmHg}$. Hal itu merupakan pengaruh degenerasi yang terjadi pada orang yang bertambah usianya (9). Berdasarkan hal ini mungkin saja ini bisa menjelaskan kenapa jumlah penderita hipertensi yang memiliki riwayat hipertensi diatas 
5 tahun lebih banyak. Hal ini sejalan dengan penelitian berdasarkan riwayat hipertensi yang $\geq 5$ tahun lebih banyak dari yang $\leq 5$ tahun adalah 46 orang $(75,4 \%)$. Dalam penelitian ini banyak yang menderita hipertensi $>5$ banyak pasien yang tidak rutin minum obat dan pola makan tidak teratur, sehingga hipertensi menjadi lama (Rahmayanti, 2018).

Tabel 8

Distribusi Frekuensi Tingkat Kecemasan di Desa Grogol tahun $2020(n=58)$

\begin{tabular}{ccc}
\hline Variabel & Frekuensi (f) & $\begin{array}{c}\text { Persentase } \\
(\%)\end{array}$ \\
\hline Tidak Ada & 11 & 19.0 \\
Kecemasan & & \\
Kecemasan Ringan & 31 & 53.4 \\
Kecemasan Sedang & 16 & 27.6 \\
\hline Total & 58 & 100.0 \\
\hline
\end{tabular}

Berdasarkan tabel 8 diketahui distribusi frekuensi data demografi responden dengan tingkat kecemasan paling banyak adalah kecemasan ringan sebanyak 31 orang (53.4\%). Kondisi kesehatan yang menganggu. Kecemasan adalah kekhawatiran yang tidak jelas dan menyebar, yang berkaitan dengan perasaan tidak pasti dan tidak berdaya dengan keadaan emosi yang tidak memiliki objek. Kecemasan pada umumnya bersifat subjektif yang dirtandai dengan adanya perasaan tegang, khawatir takut dan disertai adanya perubahan fisiologis, seperti denyut nadi, perubahan pernapasan dan tekanan darah. Kecemasan adalah gangguan alam perasaan yang ditandai dengan perasaan ketakutan atau kekhawatiran yang mendalam dan berkelanjutan, tidak mengalami gangguan dalam menilai realitas, kepribadian masih tetap utuh, kepribadian dapat terganggu oleh batas-batas normal (Hawari, 2013).

Seorang yang lama menderita hipertensi mungkin akan menjadi cemas disebabkan penyakit hipertensi yang cenderung memerlukan pengobatan yang relatif lama, terdapat risiko komplikasi dan dapat memperpendek usia (Hawari, 2014). Tekanan darah tinggi jika tidak ditangani atau diobati, dalam jangka panjang akan merusak pembuluh darah diseluruh tubuh, kompilkasi yang bisa ditimbulkan karena hipertensi adalah Stroke, retinopati diabetik, kerusakan ginjal, gagal ginjal dan jantung coroner (Wijaya, 2013). Hal ini sejalan dengan penelitian faktor lain yang mempengaruhi rendahnya tingkat kecemasan adalah pengalaman. Pasien yang pernah sakit tentu akan lebih merasa tenang karena sudah mengerti cara mengatasi masalah kesehatan dengan cara alami (Rizal, 2019). 
Tabel 9

Hubungan Lama Menderita Hipertensi Dengan Tingkat Kecemasan Pada Responden Di Desa Grogol Tahun $2020(n=58)$

\begin{tabular}{|c|c|c|c|c|c|c|c|c|c|c|}
\hline \multirow{2}{*}{\multicolumn{2}{|c|}{ Variabel }} & \multicolumn{6}{|c|}{ Tingkat Kecemasan } & \multirow{2}{*}{\multicolumn{2}{|c|}{ Total }} & \multirow{3}{*}{$\begin{array}{c}\text { Hasil } \\
\text { Analisis }\end{array}$} \\
\hline & & \multicolumn{2}{|c|}{$\begin{array}{l}\text { Tidak ada } \\
\text { kecemasan }\end{array}$} & \multicolumn{2}{|c|}{ Ringan } & \multicolumn{2}{|c|}{ Sedang } & & & \\
\hline & & $\mathrm{n}$ & $\%$ & $\mathrm{~N}$ & $\%$ & $\mathrm{n}$ & $\%$ & $\mathrm{n}$ & $\%$ & \\
\hline \multirow{3}{*}{$\begin{array}{l}\text { Lama } \\
\text { Menderita } \\
\text { Hipertensi }\end{array}$} & $\begin{array}{l}1-5 \\
\text { tahun }\end{array}$ & 6 & 10.3 & 8 & 13.8 & 1 & 1.7 & 15 & 25.9 & \multirow{4}{*}{$\begin{array}{l}\mathrm{r}=0,417 \\
\mathrm{p}=0,000\end{array}$} \\
\hline & $\begin{array}{l}6-5 \\
\text { tahun }\end{array}$ & 3 & 5.2 & 13 & 22.4 & 3 & 5.2 & 19 & 32.8 & \\
\hline & $\begin{array}{l}>11 \\
\text { tahun }\end{array}$ & 2 & 3.4 & 10 & 17.2 & 12 & 20.7 & 24 & 41.4 & \\
\hline Total & & 11 & 19.0 & 31 & 53.4 & 16 & 27.6 & 58 & 100.0 & \\
\hline
\end{tabular}

Berdasarakan tabel 9 jumlah responden dengan lama menderita hipertensi 1-5 tahun yang tidak ada kecemasan sebanyak 6 orang (10,3\%), kecemasan ringan 8 orang $(13,8 \%)$, kecemasan sedang 1 orang $(1,7 \%)$. Kemudian jumlah Responden dengan lama menderita hipertensi 6-10 tahun yang tidak mengalami kecemasan sebanyak 3 orang $(5,2 \%)$, kecemasan ringan 13 orang $(22,4 \%)$, kecemasan sedang 3 orang $(5,2 \%)$. Sedangkan jumlah responden dengan lama menderita hipertensi $>11$ tahun yang tidak mengalami kecemasan sebanyak 2 orang $(3,4 \%)$, kecemasan ringan 10 orang $(17,2 \%)$, kecemasan sedang 12 orang (20,7\%). Berdasarkan tabel 9 terlihat bahwa nilai kendall's tau antara lama menderita hipertensi dan tingkat kecemasan diketahui sebesar 0,417 dengan nilai signifikan $0,000(<0,05)$. Hasil uji menunjukan nilai signifikan 0,000 dan kurang dari 0,05 , maka dapat di interprestasikan bahwa hubungan antara lama menderita hipertensi dengan tingkat kecemasan adalah signifikan yang berarti ada hubungan yang nyata antara lama menderita hipertensi dengan tingkat kecemasan pada penderita hipertensi di desa Grogol. Keeratan hubungan antara variabel lama menderita hipertensi dengan tingkat kecemasan adalah cukup. Arah hubungan variabel lama menderita hipertensi dengan tingkat kecemasan memiliki arah hubungan yang positif, maka dapat diartikan semakin lama menderita hipertensi maka semakin tinggi tingkat kecemasan yang dialami penderita hipertensi.

Hasil penelitian Lama hipertensi dan skor kecemasan diketahui sebesar 0.749 dengan nilai signifikansi $0.00(<0.05)$. Hasil uji menunjukkan nilai signifikansi 0.00 dan kurang dari 0.05, maka dapat diinterprestasikan bahwa hubungan antara lama hipertensi dengan tingkat kecemasan adalah signifikan. Hal ini dapat dinyatakan bahwa ada hubungan yang signifikan antara lama hipertensi dengan tingkat kecemasan responden. Semakin lama responden mengalami hipertensi, semakin tinggi tingkat kecemasan yang dirasakan responden (Laksita, 2016).

Komplikasi dari hipertensi juga merupakan faktor yang menyebabkan kecemasan pada pasien, kecemasan ini muncul karena ketakutan kondisi yang lebih buruk akan terjadi, hal tersebut yang membuat pasien mengalami kecemasan berat. Kehilangan pekerjaan akan membuat seseorang mengalami kecemasan. Pasien yang mengalami komplikasi hipertensi seperti stroke akan menyebabkan keterbatasan 
mobilitas fisik sehingga berpengaruh terhadap aktivitas. Keterbatasan mobilitas fisik akan menghambat pekerjaan seseorang, terhambatnya pekerjaan membuat seseorang kehilangan peran, status dan kekuasaan. Kondisi ini menimbulkan masalah psikologis seseorang karena tidak siap terhadap situasi yang dihadapi sehingga terjadinya kecemasan. Faktor lain yang menyebabkan kecemasan adalah ekonomi, keterbatasan ekonomi akan menimbulkan respon cemas. Berbagai jenis pekerjaan akan menimbulkan respon cemas atau tekanan psikis yang berbeda akibat penghasilan yang dimiliki, pasien yang tidak mempunyai penghasilan tetap dan ingin melakukan pengobatan cenderung mengalami kecemasan. Seorang yang lama menderita hipertensi mungkin akan menjadi cemas disebabkan penyakit hipertensi yang cenderung memerlukan pengobatan yang relatif lama, terdapat risiko komplikasi dan dapat memperpendek usia (Hawari, 2013). Tekanan darah tinggi jika tidak ditangani atau diobati, dalam jangka panjang akan merusak pembuluh darah diseluruh tubuh, kompilkasi yang bisa ditimbulkan karena hipertensi adalah Stroke, retinopati diabetik, kerusakan ginjal, gagal ginjal dan jantung coroner (Wijaya, 2013).

\section{SIMPULAN DAN SARAN \\ Simpulan}

Karakeristik responden pada penelitian ini rata-rata umur reseponden dalam penelitian ini adalah 62 tahun dan standar devisiasi $\pm 10,208$. Tekanan darah responden sebagian besar hipertensi sedang 28. Responden sebagian besar berjenis kelamin perempuan sebanyak 41 orang, pendidikan responden paling banyak tidak sekolah sebanyak 24 orang, pekerjaan responden paling banyak tidak bekerja sebanyak 29 orang, responden sebagian besar tidak mempunyai komplikasi penyakit sebanyak 44 orang. Responden paling banyak dengan lama menderita hipertensi $>11$ tahun sebanyak 24 orang. Responden dengan kecemasan paling banyak mengalami kecemasan ringan sebanyak 31 orang.

Ada hubungan antara lama menderita hipertensi dengan tingkat kecemasan pada penderita hipertensi di Desa Grogol dengan nilai $P$ value $=0,000<\alpha=0,05$. maka dapat di interprestasikan bahwa hubungan antara lama menderita hipertensi dengan tingkat kecemasan adalah signifikan yang berarti ada hubungan yang nyata antara lama menderita hipertensi dengan tingkat kecemasan.

\section{Saran}

Bagi institusi kesehatan untuk melakukan screening kesehatan terutama hipertensi agar mencegah kecemasan. Bagi peneliti selanjutnya melakukan penelitian yang sama dengan mengendalikan faktor komplikasi dari hipertensi.

\section{UCAPAN TERIMAKASIH}

1. Ketua STIKES Muhammadiyah Klaten yang telah memfasilitasi jalannya penelitian

2. Responden, kader desa dan perangkat desa setempat

\section{DAFTAR PUSTAKA}

Arifin, M.H.B.M, Weta, I.W. \& Ratnawati, N.L.K.A. (2016). Faktor faktor yang berhubungan dengan kejadian hipertensi pada kelompok lanjut usia di wilayah kerja UPT Pusesmas petang 1 kabupaten bandung tahun 2016. 
Hawari, D. (2013). Manajemen stres cemas dan depresi. Jakarta.

Istirokah, I., Surtiningsih, A., \& Nurulita, U. (2017). Pengaruh terapi tertawa terhadap penurunan tingkat kecemasan pada penderita hipertensi di wilayah kerja puskesmas pengandan semarang.

Laka, O. K., Widodo, D., \& Rahayu H. W., (2018). Hubungan Hipertensi dengan Tingkat Kecemasan pada Lansia di Posyandu Lansia Desa Banjarejo Kecamatan Ngantang Malang.

Laksita I dwi. (2016). Hubungan lama menderita hipertensi dengan tingkat kecemasan pada lansia di desa paron nusukan surakarta.

Lumi, F., Terok, M., \& Budiman, F. (2018). Hubungan Derajat Penyakit Hipertensi Dengan Tingkat Kecemasan Pada Kelompok Lanjut Usia Di Wilayah Kerja Puskesmas Kahakitang Kecamatan Tatoareng. Politeknik Kesehatan Makassar.

Rahmayanti Y. (2018). Hubungan lama menderita hipertensi dengan penurunan fungsi kognitif pada lansia;02:241-6.

Riskesdas. (2013). Prevelensi Hipertensi di Indonesia.

Rizal, H., Rizani, A., \& Marwansyah, H. (2019). Gambaran Tingkat Kecemasan Pasien Hipertensi Dengan Komplikasi Dan Non Komplikasi Di Ruang Poli Klinik RSUD Banjabaru. J Citra Keperawatan; 6(1):18-24.

Suliswati. (2012). Konsep Dasar Keperawatan Kesehatan Jiwa. Jakarta: Penerbit Buku Kedokteran EGC.

Susila \& Suyanto. (2015). Metodologi Penelitian Cross Sectional. Klaten: Bosscript.

Wijaya, A. S. \& Putri YM. (2013). Keperawatan Medikal Bedah 1. Yogyakarta: Nuha Medika 